\section{Parliament in Britain}

\author{
by our Parliamentary Correspondent \\ Science in Hospitals
}

Mr Davtd Ennals, for the Department of Health and Social Security, welcomed the publication of the report on Hospital Scientific and Technical Services prepared by the committee under Sir Solly Zuckerman. 'The Government, he said, agreed that administrative arrangements should be made to improve operational planning of seientific and technical services; hospital authoritics were being consulted. In reply to points raised by $\mathrm{Mr}$ Maurice Macmillan, $\mathrm{Mr}$ Ennals said that the widest consultation would take place, and that the place of the teaching hospitals would "in no way be vitiated by the recommendations if they were carried through". (Statement, December 6.)

\section{Overseas Students}

Mrs Shirley Williams said that there are now 15,497 overscas students in British universities, and another 15,401 in other grant-aided further education establishments: 7,761 had received support from public funds for the relicf of hardship after the introduction of higher fees, and this cost a total of $£ 444,000$. (Written answer, December 6.)

\section{Research Associations}

Mr Gerry Fowlez provided Mr Will Owen with a useful list which details the grants paid by the Ministry of Technology to each of the forty-three research associations which are now aided. The Ship Research Association does best, with a grant of just over $£ 500,000$. The Welding $\mathrm{RA}$ receives almost $£ 300,000$, the Seientific Instrument RA about $£ 200,000$, and the Construction Industry RA some $£ 180,000$. (Written answer, December 6.)

Power

WILL Drax B power station be fuelled by coal ? This is the question which was exercising Mr George Jeger last week. Mr Roy Mason pointed out that the CEGB already has statutory permission to build a coal-fired extension to Drax, but that it was not in the current investment programme. The start on Drax 2 would depend on the demand for electricity, and the growth of competing fuels. That cannot have been much of a comfort to Mr Jeger, who said that there were fears and suspicions in the area about the CEGB's intentions. (Oral answer, December 10.)

\section{Motorway Box}

Mr HugII Jenkins asked the Minister of Transport what was being done to compensate house-owners for the decline in value of their property which would result from the building of the Motorway Box. $\mathrm{Mr}$ Richard Marsh said that the subject formed part of a general study on compensation coordinated by the Ministry of Housing and Local Government. $\mathrm{Mr}$ Jenkins suggested that it might be better to put the box further out of London, but Mr Marsh was not to be drawn. (Oral answers, December 9.)

\title{
How to dam the English Channel
}

THE competition to build a Channel dam (Nature, 219, 991 ; 1968) attracted close on a score of entries. In the circumstances, it is not surprising that none of them really questioned the feasibility of damming the Channel-the competition, after all, was intended to answer the question how to build a dam and not whether to build one. The particular suggestions put forward by the competitors are not always sufficiently informed by the thorough understanding of the oceanographic and geological conditions in the English Channel which a successful project to construct a dam would have somehow to exploit. As with many other contemporary problems, it seems quite plain that more research is urgently necessary.

What follows is a brief account of some of the more interesting of the proposals to dam the English Channel. It is hoped that these will stimulate further discussion and that the result will be a deeper understanding of the problems.

One of the most detailed entries was submitted by Mr CLAUDE HARDY, who lives and works in Paris. Mr Hardy has been advocating the construction of a Channel dam for more than two decades. He advocates a simple earth and rock filled dam extending some 32 kilometres between South Foreland and Cap Gris Nez. In Mr Hardy's view, the dam could be combined with impounding pools which could be used to generate $35 \times$
$10^{9} \mathrm{kWh}$ of electricity a year and thus make a substantial contribution to the supply of energy in Britain. Mr Hardy is also impressed with the ease with which a fixed barrage across the Channel would enable surface transport to flow between Britain and the mainland.

As with many other schemes, Mr Hardy's method of constructing the dam relies on the comparatively shallow depth of the Channel between Britain and France-an average of 20 fathoms (120 feet) and a maximum of 30 fathoms ( 180 feet). In this view of the

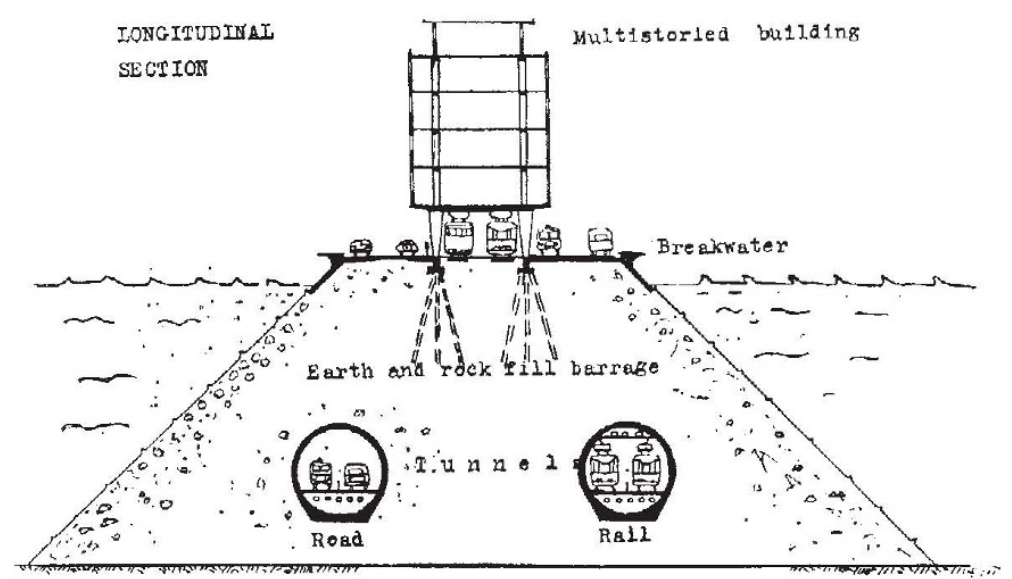

Fig. I. 
dam building operation, constructional materials would be dredged from the bottom of the Channel as in the building of the Dutch dykes (where facing material is, however, imported from elsewhere by barge). Mr Hardy would provide locks through which Channel shipping could pass and he would use for transport across the Channel not merely the upper surface of the barrage but also tunnels buried within it (Fig. 1). Mr Hardy differs from other competitors in his recognition that the project would in part be affected by the presence of sand banks in the Channel coming to within a few feet of the low tide mark as well as by the fact that the flow of water in the Channel is predominantly from the Atlantic to the North Sea. $\mathrm{He}$ calculates that there is a net transport of roughly 2.5 cubic kilometres a day of water into the North Sea, but it is not clear precisely how he would make use of these characteristics of the English Channel. $\mathrm{Mr}$ Hardy also argues that the interference with shipping along the Channel would be much reduced if the Channel dam were itself to become a terminus for much of this traffic-a kind of Europort on the sea.

Mr A. D. PENMAN and Dr J. B. BURLAND point out that the proposal for a causeway between France and Britain was originally described by a Swiss engineer in his evidence in 1929 to a Parliamentary committee on the Channel tunnel. They argue that a rock and earth filled dam (see Fig. 2) would be practicable. To allow for the tidal range in the English Channel, the crest of the dam would have to be about 10 metres above the Newlyn datum, which implies that the maximum height of the dam would be 72 metres. This, the argument goes, is entirely comparable with the height of dams at present being built in Britain. The section of the dam would consist of a sand core surrounded by zones of chalk and, on the outside, with shoulders of French granite. If the width of the crest is fixed at 82 metres, it is estimated that the volume of material needed to construct the dam would be $280 \times 10^{6}$ cubic metres which, Mr Penman and Dr Burland estimate, could be obtained at a cost of $£ 168$ million. This sum does not of course include the cost of the road works nor that of the wave protection and the shipping facilities which, it is argued, would best be provided at the two ends of the barrage.

Other competitors were, however, sceptical of the feasibility of an earth filled dam-everything depends on the average depth of the structure. (Nobody seems to have worked with a mixed construction in which an earth and rock filled dam is used in the more shallow parts of the Channel and in which a concrete structure is used elsewhere.) Mr R. E. MASSY of Richmond, California, working on the assumption that the average depth of the Channel is roughly 250 feet, proposes the construction of hollow concrete shells sunk in the Channel and later filled with sand dredged from the bottom of the Channel (Fig. 3). The difficulty here is to anchor such structures to the bottom with the kind of rigidity which cross-Channel travellers would demand. Mr STEPHEN TAIGEL proposes a scheme by means of which prefabricated units of concrete would be used to extend a pair of parallel walls out to sea from both sides of the Channel. In

his scheme, there would also be a movable closure which could be used to seal off successive sections of the dam so as to allow the construction of tunnels and other facilities to be undertaken. The movable concrete sections would then be advanced to the forward end of each sea wall so as to continue the advance of the dam towards the centre of the English Channel.

Several competitors were concerned with the problem of transporting enough solid fill to form an earth and rock filled dam and were therefore led to suggest schemes in which tubes of various kinds could be floated to the site and filled with material from the bottom of the Channel. One proposal would in effect have consisted of tubes stretching from one side of the Channel to the other and stacked in such a way as to form a barrage of pyramidal cross-section. Other versions of these schemes would have used plastic tubes filled with dredged material in situ. Unfortunately, not all of these systems seem to have been analysed with the care which an exposed position in the Channel would seem to require.

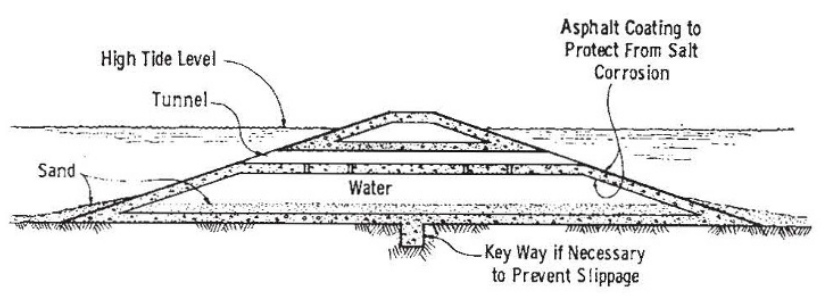

Fig. 3.

To some extent, indeed, all the entries were incomplete in their analysis of the problem. For one thing, it is clear that the building of a dam across the English Channel would have a profound effect on the tides in the North Sea. One of the most obvious effects would be reduction of the tidal range to the east of the dam which would no doubt be a matter of considerable interest to the Dutch engineers who at present lavish care and attention on the dykes.

Undoubtedly a barrier between the North Sea and the Atlantic would also set in train the rapid accumulation of dry land between Kent and Belgium although it is by no means clear how fast this process would be. It is also unclear to what extent the two prominent sand banks lying just beneath low water mark in the English Channel might be exploited in any real attempt to dam the Channel. These and other matters obviously require further study and those who would wish to take part in a serious study of them are invited to send their names to the Editor of Nature.

Those competitors who have been mentioned by name will receive a free copy of Nature during 1969. 